Guy J. Oudhuis

Dennis C. Bergmans

Tom Dormans

Jan-Harm Zwaveling

Alfons Kessels

Martin H. Prins

Ellen E. Stobberingh

Annelies Verbon

\title{
Probiotics versus antibiotic decontamination of the digestive tract: infection and mortality
}

A. Verbon (®)

Department of Internal Medicine, Erasmus Medical Centre, PO Box 2040, 3000 CA Rotterdam, The Netherlands e-mail: a.verbon@erasmusmc.nl Tel.: +31-10-7033510 Fax: +31-10-7033510
Abstract Purpose: Selective decontamination of the digestive tract (SDD) has been shown to decrease the infection rate and mortality in intensive care units (ICUs); Lactoba- cillus plantarum 299/299v plus fibre (LAB) has been used for infection prevention and does not harbour the potential disadvantages of antibiotics. The objective was to assess whether $\mathrm{LAB}$ is not inferior to SDD in infec- tion prevention. Methods: Two hundred fifty-four consecutive ICU patients with expected mechanical ventilation $\geq 48 \mathrm{~h}$ and/or expected ICU stay $\geq 72 \mathrm{~h}$ were assigned to receive SDD: four times daily an oral paste (polymyxin E, gentamicin, amphotericin B), enteral solution (same antibiotics), intravenous cefo- taxime (first 4 days) or LAB: two times daily L. plantarum 299/299v with rose-hip. Results: The primary endpoint was infection rate. A dif- ference $<12 \%$ between both groups indicated non-inferiority of LAB. The

trial was prematurely stopped after a study reporting increased mortality in critically ill pancreatitis patients receiving probiotics. No significant difference in infection rate $[31 \%$ in the LAB group, $24 \%$ in the SDD group (OR 1.68, 95\% CI 0.91-3.08; $p=0.10)$ ] was found. ICU mortality was $26 \%$ and not significantly different between the LAB and SDD groups. Gram-positive cocci and Pseudomonas aeruginosa were significantly more frequently isolated from surveillance cultures in the SDD group compared to the LAB group (for sputum: 18 vs. $10 \%$ and 33 vs. $14 \%)$. Significantly more Enterobacteriaceae were found in the $\mathrm{LAB}$ group ( 23 vs. $50 \%$ ). No increase in antibiotic resistance was found during and after SDD or LAB use. Conclusions: The trial could not demonstrate the non-inferiority of LAB compared with SDD in infection prevention. Results suggest no increased ICU mortality risk in the LAB group.

Keywords Antibiotics ·

Critical care - Lactobacillus .

Nosocomial infections · Survival and Medical Technology Assessment, Maastricht University Medical Centre, PO Box 5800, 6202 AZ Maastricht, The Netherlands 


\section{Introduction}

Intensive care unit (ICU)-acquired infections have been estimated to occur in at least $17 \%$ of patients [1] and are associated with increased ICU stay, mortality and health care costs [2]. Most of these infections are thought to be preceded by oropharyngeal and intestinal colonisation with potentially pathogenic microorganisms [3]. Selective decontamination of the digestive tract (SDD) and oropharynx (SOD), used in the ICU [4], aim at the elimination of potentially pathogenic microorganisms from the oropharyngeal cavity, stomach and gut, while leaving the anaerobic flora intact. Since the introduction of SDD, randomised clinical trials and meta-analyses have shown a decrease in mortality [5-8]. However, SDD has been associated with the emergence of antibiotic-resistant microorganisms during and after intervention [9].

A method with the beneficial effects of SDD, but without the risk of selection of antibiotic-resistant microorganisms would be ideal.

After ingestion, lactic acid bacteria and fermentable fibre enhance intestinal barrier function, and compete with pathogens for adhesion and nutrients to create an unfavourable local milieu for pathogen colonisation [10, 11]. Use of Lactobacillus plantarum $299 / 299 \mathrm{v}$ and fibre (LAB) decreased hospital-acquired infections in patients that had abdominal surgery and acute pancreatitis compared with placebo $[12,13]$. In liver transplant patients, these lactobacilli were superior to SDD in the prevention of nosocomial infections [14]. The aim of the study was to investigate whether treatment with Lactobacillus plantarum 299/299v and rose-hip is non-inferior to SDD in preventing infection in a general ICU population.

\section{Materials and methods}

Setting and participants

Consecutive patients admitted to the ICU at the Maastricht University Medical Centre (MUMC, 705 beds) and the Atrium Medical Centre Heerlen (a 545-bed teaching hospital) were enrolled from June 2005 to January 2008 and September 2006 to January 2008. The participating ICUs are similar in patient population, severity of disease (mean APACHE II scores are comparable) and mortality rates (data not shown).

Eligibility criteria were as applied before [5]. However, amphotericin B suspension and lactobacilli plus rose-hip do not pass through nasoduodenal tubes. Therefore, use of these tubes was added as an exclusion criterion, in addition to contraindications for enteral feeding.

The study protocol was approved by the institutional review boards for human studies of both participating centres. Procedures followed were in accordance with the
Helsinki Declaration of 1964. Written informed consent was obtained from patients or their legal representatives before enrolment in the trial. The trial has been registered in the Dutch Trial Register (http://www.trialregister.nl/ trialreg/index.asp), no. NTR1411.

\section{Allocation and interventions}

In the MUMC, the study had an open label, crossover of units design. The Intensive Care department consists of two separate units ( 9 and 8 beds) with different case mix and disease burden. To prevent cross-colonisation, randomisation on a patient level was not possible, and allocation on a unit level was instituted. Crossover of units was necessary to correct for possible differences in case mix, disease burden and other possible confounders. Patients were allocated to a unit by medical staff not involved in the study. In case more than one bed was available in the ICU, patients were randomly assigned to a unit. The first inclusion period lasted 18 months, followed by a wash-out period of 3 months. Due to results of the PROPATRIA trial, in which increased mortality in critically ill patients with severe pancreatitis receiving probiotics was shown [15], the second inclusion period was prematurely stopped after 11 months.

In the Atrium MC, one ICU (6 beds) participated in the study. A 10-month intervention period of LAB was followed by a 3-month wash-out period and a prematurely stopped 4-month intervention period of SDD.

Selective decontamination of the digestive tract patients received a regimen as previously described [5], except that gentamicin was applied instead of tobramycin. Topical study medication was manufactured and the quality tested by the pharmacy of the MUMC.

LAB patients received a solution of viable Lactobacillus plantarum 299/299v in a dose of $5 \times 10^{9}$ colonyforming units $(\mathrm{cfu})$ together with $6 \mathrm{~g}$ of rose-hip (Probi $A B$, Lund, Sweden). The manufactured freeze-dried powder was dissolved in $75 \mathrm{ml}$ of water and applied two times daily through a nasogastric tube.

In case of gastric retention, defined as $>1,000 \mathrm{ml} /$ $24 \mathrm{~h}$, either tube feeding was administered through a nasoduodenal tube or a prokinetic agent was prescribed at the physician's discretion. Administration of study product was continued by nasogastric tube until ICU discharge, death or final removal of the tube. Therapeutic use of antibiotics was left to the attending physician's discretion, whereas administration of prophylaxis was continued without dose adjustments.

\section{Outcomes and follow-up}

Infections were retrospectively determined using the Centres for Disease Control and Prevention (CDC) 
criteria [16] and modified CDC criteria [17] in case of clinical suspicion of a ventilator-associated pneumonia (VAP). Urinary tract infections (UTIs) were only assigned when other infections could be ruled out. Events occurring $>48 \mathrm{~h}$ after ICU admission were considered ICU-acquired. When a VAP was clinically suspected, bronchoalveolar lavage (BAL) was performed to the attending intensivist's discretion, and antibiotic therapy was started or adjusted empirically. Confirmation of clinically suspected VAP required $\geq 2 \%$ cells containing intracellular organisms and/or a quantitative culture result of $\geq 10^{4} \mathrm{cfu} / \mathrm{ml}$ in BAL fluid $[16,17]$. Two researchers (G.J.O. and A.V.) determined whether patients met the criteria of infection using predefined criteria, independently from one another and unaware of the study regimen. Necessary data were coded without information about the study arm. Whenever no consensus was reached, a third author (D.C.B.) reviewed the data.

In ICU, surveillance cultures of sputum and urine were taken twice weekly. A rectal swab was taken prior to first administration of either study product. Thereafter, swabs were taken weekly until death or a maximum of 2 weeks after ICU discharge. E. coli and enterococci were isolated from the swabs as indicator organisms. CLSI breakpoints for antibiotic resistance were applied [18]. Data on antibiotic consumption, other than SDD agents, were recorded using the anatomical therapeutic chemical (ATC) classification system and were expressed as defined daily doses (DDD) per 100 patient days [19, 20].

Medical files of patients who died during ICU stay were retrospectively screened for signs and symptoms of small bowel ischemia.

The primary endpoint was infection during ICU stay. Assuming that SDD use results in an estimated infection prevalence of $25 \%$ [21], a difference larger than half of this percentage (i.e., 12\%) had to be excluded to hypothesise an equivalent efficacy of LAB compared with SDD (non-inferiority). One hundred eighty-five patients had to be enrolled in each group, based on $\alpha=0.05$ (onesided) and a power of $80 \%$.

Early onset infections were defined as infections occurring within 48-96 h after ICU admission. Infection at ICU admission was defined as a combination of clinical diagnosis of infection by the attending intensivist and antibiotic use at admission.

Secondary endpoints were ICU mortality and in-hospital mortality. In-hospital mortality was not regarded as a proper endpoint within this open label study design [7, 22, 23 ] and was retrospectively discarded. Mortality at day 28 was added.

Other secondary endpoints were additional use of systemic antibiotics and prevalence of (antibiotic-resistant) microorganisms in surveillance cultures.
Statistical analysis

To compare specific variables, the Pearson $\chi^{2}$ and MannWhitney $U$ test were used. A two-way contingency table analysis was performed to calculate differences in proportions, regarding patients with infectious events, and the respective $95 \%$ confidence intervals (CI). Logistic regression models, regarding mortality and proportion of patients with infections, were used to adjust for differences in prognostic variables and severity of disease, using the APACHE II score [7, 24], age [7], sex [7], BMI [25] and ICU as covariates.

For time-to-infectious event analysis, a Kaplan-Meier curve with log rank test was generated. Analysis was done with SPSS 15.0 for Windows (SPSS Benelux BV, Gorinchem, The Netherlands). A Poisson analysis, with the number of infections per patient as dependent variable, and the intervention and the above-mentioned covariates as independent variables, was performed using STATA 10.0 (STATA Corporation, College Station, TX). All analyses were based on the intention-to-treat principle. No interim analysis was performed because of the crossover design. Statistical significance was defined as a $p$ value of less than 0.05 in all cases.

\section{Results}

Patient population

Enrolment involved 254 consecutive ICU patients (i.e., $73 \%$ of eligible patients, Fig. 1), 222 in the MUMC and 32 in the Atrium MC. Inclusion rates were similar in both hospitals. Both study groups were comparable for all baseline and follow-up characteristics (Table 1), as were patients in the two participating centres (data not shown). The prevalence of infection at admission was $39 \%$ in the SDD group and $32 \%$ in the LAB group $(p=0.29)$.

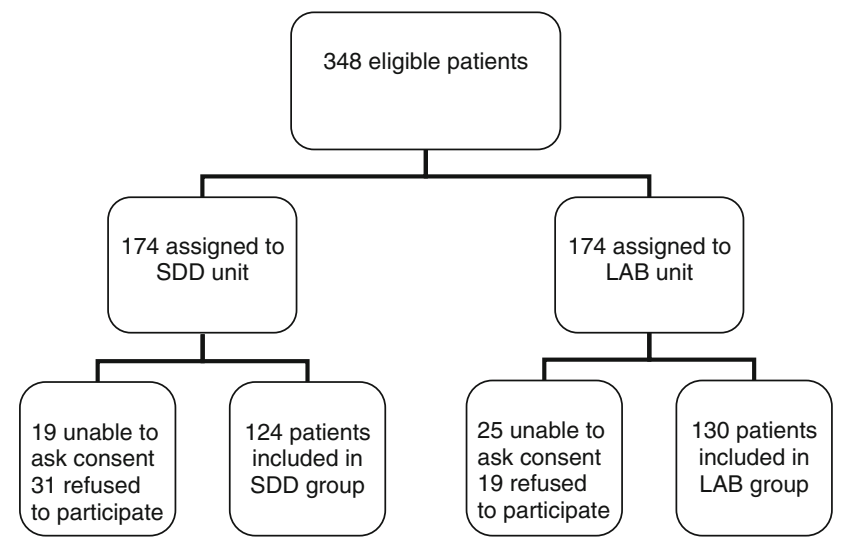

Fig. 1 Flowchart of patient enrolment. $S D D$ selective decontamination of the digestive tract, $L A B, L$. plantarum 299/299v plus fibre 
Table 1 Characteristics of the study population

\begin{tabular}{|c|c|c|c|}
\hline Characteristic & $\begin{array}{l}\text { LAB } \\
\text { group } \\
(n=130)\end{array}$ & $\begin{array}{l}\text { SDD } \\
\text { group } \\
(n=124)\end{array}$ & $p$ Value \\
\hline \multicolumn{4}{|l|}{ Sex } \\
\hline Male $(\%)$ & $84(65)$ & $73(59)$ & 0.35 \\
\hline \multicolumn{4}{|l|}{ Age in years } \\
\hline Mean (SD) & $63.5(16.4)$ & $61.9(16.0)$ & \multirow{2}{*}{0.26} \\
\hline Range & $20-90$ & $17-90$ & \\
\hline \multicolumn{4}{|l|}{$\mathrm{BMI}$ in $\mathrm{kg} / \mathrm{m}^{2}$} \\
\hline Mean (SD) & $25.5(4.9)$ & $25.4(4.5)$ & \multirow[t]{2}{*}{0.98} \\
\hline Range & $17.3-55.9$ & $16.6-47.8$ & \\
\hline \multicolumn{4}{|l|}{ APACHE II score } \\
\hline Mean (SD) & $23(7.7)$ & $21(7.6)$ & \multirow[t]{2}{*}{0.11} \\
\hline Range & $7-44$ & $7-40$ & \\
\hline \multicolumn{4}{|l|}{ Days in hospital } \\
\hline Mean (SD) & 36.7 (33.9) & $38.5(33.5)$ & \multirow[t]{2}{*}{0.35} \\
\hline Range & $2-193$ & $1-227$ & \\
\hline \multicolumn{4}{|l|}{ Days in ICU } \\
\hline Mean (SD) & $18.0(24.8)$ & $15.0(17.8)$ & \multirow[t]{2}{*}{0.78} \\
\hline Range & $1-155$ & $1-105$ & \\
\hline \multicolumn{4}{|c|}{ Reason for ICU admission (\%) } \\
\hline Respiratory insufficiency & $46(35.4)$ & $39(31.5)$ & \multirow{6}{*}{0.68} \\
\hline Neurological & $31(23.8)$ & $36(29.0)$ & \\
\hline Hemodynamic & $13(10.0)$ & $9(7.3)$ & \\
\hline Sepsis/shock & $17(13.1)$ & $21(16.9)$ & \\
\hline Peritonitis & $9(6.9)$ & $5(4.0)$ & \\
\hline Trauma/other $^{\mathrm{a}}$ & $14(10.8)$ & $14(11.3)$ & \\
\hline \multicolumn{4}{|l|}{ Admission group (\%) } \\
\hline Surgical & $64(49.2)$ & $69(55.6)$ & \multirow{3}{*}{0.49} \\
\hline Medical & $62(47.7)$ & $50(40.3)$ & \\
\hline Trauma & $4(3.1)$ & $5(4.0)$ & \\
\hline Patients on MV (\%) & $129(99.2)$ & $119(96.0)$ & 0.09 \\
\hline \multicolumn{4}{|l|}{ Days on MV } \\
\hline Mean (SD) & $16.7(23.6)$ & $14.1(17.2)$ & \multirow[t]{2}{*}{0.60} \\
\hline Range & $2-152$ & $1-100$ & \\
\hline \multicolumn{4}{|c|}{ Number of days with administration of study product ${ }^{b}$} \\
\hline Mean (SD) & $11.0(14.3)$ & $10.5(13.8)$ & \multirow{2}{*}{0.87} \\
\hline Range & $0-73$ & $0-94.25$ & \\
\hline \multicolumn{4}{|c|}{ Cumulative gastric retention in milliliters } \\
\hline Mean (SD) & $3,002(6,368)$ & $2,264(3,713)$ & \multirow[t]{2}{*}{0.74} \\
\hline Range & $0-53,670$ & $0-23,885$ & \\
\hline
\end{tabular}

$L A B$ L. plantarum 299/299v plus fibre; $S D D$ selective decontamination of the digestive tract; $B M I$ body mass index; $A P A C H E$ acute physiology and chronic health evaluation; $I C U$ intensive care unit; $M V$ mechanical ventilation

a Including acidosis, bowel ischemia, meningitis, renal insufficiency, weaning problems, Guillain-Barré syndrome, retroperitoneal haematoma, pancreatitis, encephalopathy, necrotising fasciïtis, pelvic exenteration, traumatic spinal cord injury

b In LAB group two times daily, in SDD group four times daily

\section{ICU-acquired infections}

The acquired infection rate was $28 \%$ (70/254); 40 of 130 patients given $\mathrm{LAB}(31 \%)$ and 30 of 124 patients receiving SDD (24\%, Table 2). Adjusted for BMI, age, sex, APACHE II score and ICU, the difference between both groups was not statistically significant [odds ratio (OR) $1.68,95 \%$ CI $0.91-3.08 ; p=0.10]$. The time to infection was similar in both study groups $(p=0.38$, Fig. 2). When UTIs were excluded from the analysis, differences remained non-significant (OR $1.23,95 \% \mathrm{CI}$
Table 2 Number and type of infectious events

\begin{tabular}{|c|c|c|}
\hline Type of infection & $\begin{array}{l}\text { LAB group } \\
(n=130)\end{array}$ & $\begin{array}{l}\text { SDD group } \\
(n=124)\end{array}$ \\
\hline Total events $(\%)^{*}$ & $67(100)$ & $42(100)$ \\
\hline Ventilator-associated pneumonia (\%) & $10(14.9)$ & $9(21.4)$ \\
\hline Pneumonia $^{\mathrm{a}}(\%)$ & $2(3.0)$ & - \\
\hline Urinary tract infection $(\%)$ & $30(44.8)$ & $8(19.0)$ \\
\hline $\begin{array}{l}\text { (Catheter-related) bloodstream } \\
\text { infection }(\%)\end{array}$ & $16(23.9)$ & $16(38.1)$ \\
\hline Wound infection (\%) & $2(3.0)$ & $3(7.1)$ \\
\hline Intra-abdominal infection $(\%)$ & $4(6.0)$ & $3(7.1)$ \\
\hline Other $^{\mathrm{b}}(\%)$ & $3(4.5)$ & $3(7.1)$ \\
\hline \multicolumn{3}{|l|}{ Number of infections $* *$} \\
\hline Patients with 0 infections (\%) & $90(69.2)$ & $94(75.8)$ \\
\hline Patients with 1 infection (\%) & $23(17.7)$ & $20(16.1)$ \\
\hline Patients with 2 infections (\%) & $12(9.2)$ & $9(7.3)$ \\
\hline Patients with $\geq 3$ infections (\%) & $5(3.8)$ & $1(0.8)$ \\
\hline
\end{tabular}

$L A B$ L. plantarum $299 / 299$ v plus fibre; $S D D$ selective decontamination of the digestive tract

$* p=0.25$

** $p=0.35$

${ }^{a}$ Involved patients were not mechanically ventilated

b Including (pulmonary) abcess, sinusitis, empyema

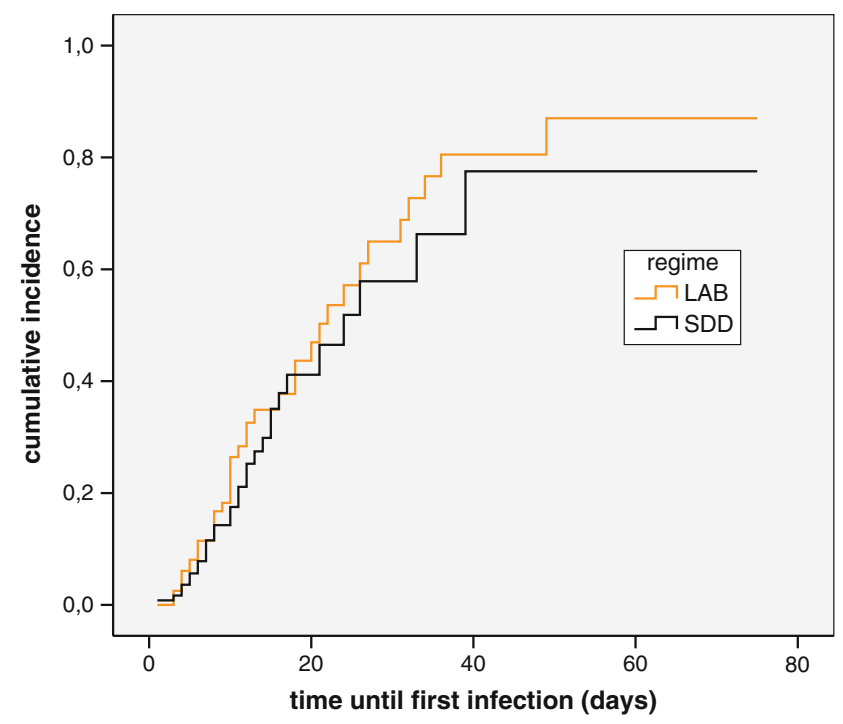

Fig. 2 Kaplan-Meier time-to-event analysis for the incidence of infectious events. $p=0.38$, by $\log$ rank test. SDD, selective decontamination of the digestive tract; LAB, L. plantarum 299/ 299v plus fibre

$0.63-2.40 ; p=0.54$ for infections and $p=0.90$ for time to infection). The total number of infections was not significantly different $(p=0.25$, Table 2$)$, nor was the number of infections per patient with $(p=0.35$, Table 2$)$ or without UTIs ( $p=0.43$, data not shown). In the SDD group, nine episodes of VAP occurred during 1,674 days of mechanical ventilation (MV, 5.4 VAPs/1,000 days). In the LAB group, ten episodes of VAP occurred during 2,156 days of MV (4.6 VAPs/1,000 days, N.S.). Four out 
of 30 infectious events in the SDD group were early onset $(13.3 \%)$ versus $7 / 40$ in the LAB group $(17.5 \%$, $p=0.64)$. The difference in infection rate between both study groups was $7 \%(95 \% \mathrm{CI}-4.4$ to $17.1 \%)$ in the 254 included patients. When extrapolated to the calculated necessary sample size of 370 patients, the $95 \%$ CI ranged from -2.6 to $15.3 \%$. With UTIs excluded, the difference in infection rate was $2 \%(95 \%$ CIs -8.3 to $10.9 \%$ and -7 to $9.1 \%$, respectively).

The absolute number of Gram-positive cocci and $P$. aeruginosa causing infections was comparable between both groups. However, proportionally, significant differences in prevalence were present (Table 3 ). Between both groups, no significant differences in antibiotic resistance of microorganisms of the same species were found during the study period for any antibiotic. Moreover, resistance levels did not increase over time.

\section{Mortality}

Overall ICU mortality was $26 \%$. ICU mortality, adjusted for the above-mentioned confounders, was not significantly different between SDD and LAB (OR 0.99, 95\% CI $0.51-1.92 ; p=0.97)$, nor was adjusted mortality at day 28 (OR $1.31,95 \%$ CI $0.68-2.53 ; p=0.43$ ). Mortality rates were similar for both participating centres. No patients receiving LAB or SDD developed bowel ischemia as considered by autopsy and/or chart review.

\section{Additional antibiotic use}

The total mean number of $\mathrm{DDD} / 100$ patient days was significantly higher in the LAB group than in the SDD group (141.7 vs. $108.7, p=0.008$, Table 4 ). This could be explained by the significantly higher use of co-amoxiclav in the LAB group ( $p=0.003$, Table 4$)$. During the first $72 \mathrm{~h}$ after ICU admission, 103 SDD patients and 108

Table 3 Microorganisms that caused infectious events

\begin{tabular}{lll}
\hline & LAB group & SDD group \\
\hline Total number of microorganisms (\%) & $97(100)$ & $51(100)$ \\
Gram-positive & $10(10)$ & $11(22)^{*}$ \\
Enterococcus species (\%) & $7(7)$ & $10(20)^{*}$ \\
Coagulase-negative staphylococci (\%) & $6(6)$ & $3(6)$ \\
Staphylococcus aureus (\%) & $4(4)$ & $2(4)$ \\
Other (\%) & $10(10)$ & $12(24)^{*}$ \\
Gram-negative & $44(45)^{*}$ & $9(18)$ \\
Pseudomonas aeruginosa (\%) & $7(7)$ & $1(2)$ \\
Enterobacteriaceae (\%) & $9(9)$ & $3(6)$ \\
Other (\%) & & \\
Candida species (\%) &
\end{tabular}

$* p<0.05$

$L A B$ L. plantarum $299 / 299$ v plus fibre; $S D D$ selective decontamination of the digestive tract
Table 4 Additional antibiotic use in both study groups in mean DDD/100 patient days

\begin{tabular}{lcc}
\hline Antibiotic & SDD group & LAB group \\
\hline Amoxicillin & 4.8 & 5.7 \\
Piperacillin & 2.5 & 0.9 \\
Flucloxacillin & 8.4 & 15.3 \\
Co-amoxiclav & 34.7 & $49.3^{* *}$ \\
Piperacillin-tazobactam & 9.4 & 12.8 \\
Cefazoline & 2.1 & 0.5 \\
Cefuroxime & 0.8 & - \\
Ceftazidime & 2.9 & 0.7 \\
Ceftriaxone & 0.5 & $7.7^{* *}$ \\
Carbapenems & 2.7 & 0.9 \\
Co-trimoxazol & 1.2 & 3.0 \\
Macrolides $/$ clindamycin & 5 & 2.9 \\
Gentamicin & 3.4 & 8.5 \\
Fluoroquinolones & 15.5 & 22.0 \\
Vancomycin & $4.6^{*}$ & 1.1 \\
Other & 10.2 & 10.4 \\
Total & 108.7 & $141.7^{* *}$ \\
\hline
\end{tabular}

Antibiotics for systemic administration, unless stated otherwise. $D D D$ defined daily dose; $S D D$ selective decontamination of the digestive tract; $L A B$ L. plantarum 299/299v plus fibre

$* p<0.05$, by Mann-Whitney $U$ test

** $p<0.01$, by Mann-Whitney $U$ test

a Clarithromycin was administered orally

b Including benzylpenicillin, aztreonam, metronidazol, rifampicin and colistin

LAB patients used a total of $368 \mathrm{DDD}$ and $411 \mathrm{DDD}$, with a mean of 3.6 and 3.8 DDD/patient (N.S.), respectively.

\section{Surveillance cultures}

In 64 patients, 277 isolates were cultured from 215 positive sputum samples in the SDD group and 516/326 from 73 patients in the LAB group $(p<0.001)$. Significantly more Gram-positive cocci (50/277 isolates vs. 52/516, 25 vs. 23 patients) and Pseudomonas aeruginosa (92/277 vs. $70 / 516,18$ vs. 14 patients) were cultured in the SDD group ( $p=0.001$ and $p<0.001$, respectively), whereas more Enterobacteriaceae (63/277 vs. 259/516, 24 vs. 57 patients) and Acinetobacter species (1/277 vs. 23/516, 1 vs. 4 patients) were found in the LAB group ( $p<0.001$ and $p=0.001$, respectively).

In 22 patients, 57 isolates were cultured from 54 positive urine samples in the SDD group and 136/111 from 42 patients in the LAB group $(p<0.001)$. The prevalence of enterococci (10/57 isolates vs. $12 / 136,8$ vs. 7 patients) and $P$. aeruginosa (14/57 vs. $10 / 136,6$ vs. 6 patients) was higher in the SDD group ( $p=0.08$ and $p=0.001$, respectively), and of Enterobacteriaceae (for E. coli $7 / 57$ vs. $38 / 136,4$ vs. 18 patients) in the LAB group $(p=0.02)$.

The prevalence of enterococci in rectal swabs (not different at $t=0$ ) significantly increased over time 
during prophylaxis with both $\mathrm{SDD}$ and $\mathrm{LAB}$, to a respective maximum of 96 and $88 \%$ (N.S.). After cessation of prophylaxis, this increased percentage persisted. The prevalence of $E$. coli (not different at $t=0$ ) diminished over time during prophylaxis to 0 and $24 \%$, respectively $(p<0.001)$. After cessation of prophylaxis, the prevalence tended to increase (N.S.).

Antibiotic resistance among Enterobacteriaceae, nonfermenting species other than Pseudomonas, Candida species, staphylococci and enterococci in sputum and urine samples did not differ significantly between both study groups at any time point throughout the entire study period (data not shown). Among P. aeruginosa isolates, resistance to ceftazidime $(p=0.02)$, ciprofloxacine $(p<0.001)$, piperacillin $(p=0.004)$ and piperacillin-tazobactam $(p=0.02)$ was significantly higher in the LAB group than in the SDD group. Prevalence of resistance in both groups did not increase significantly over time. No putative ESBL producers were found among Klebsiella pneumoniae isolates.

\section{Discussion}

This trial failed to demonstrate non-inferiority of the probiotic L. plantarum 299/299v plus rose-hip (LAB) compared with SDD in prevention of ICU-acquired infections. Rather, the results suggest that LAB might be inferior to SDD. The difference in ICU mortality and mortality at day 28 was not statistically significant between both groups. No significant difference in prevalence of antibiotic-resistant bacteria was recorded between clinical isolates of 130 patients receiving $\mathrm{LAB}$ and 124 patients receiving SDD.

Infection rates in ICU studies have been shown to vary from 28 to $90 \%$ when no infection prevention regimen is used [12, 15, 26, 27]. Infection rates using probiotics for prevention varied from 10 to $30 \%$ [12, 14, 15]. Using $\mathrm{LAB}$, an infection rate of $31 \%$ was found in our study. A large proportion of these infections was due to UTIs (Table 2), which seemed to be prevented by SDD. Exclusion of UTIs resulted in a rate of $21 \%$ in the LAB group. The higher additional antibiotic use in the LAB group, in particular co-amoxiclav, may have masked or prevented infectious complications.

The infection rates with SDD in our study were lower than those previously reported $(34-43 \%)$ [6, 28]. The proportional differences in prevalence of microorganisms (of infectious events as well as surveillance cultures) between both study groups were as expected, since SDD mainly eliminates Enterobacteriaceae [29]. Resistance levels among bacteria causing infections were comparable to those described in Dutch ICUs [30].

The overall mortality rate of $26 \%$ in the present study was within the range described by Knaus et al. [24] for (a group of) patients with a (mean) APACHE II score of 22. The ICU mortality in the LAB group was not significantly different from that in the SDD group. SDD has already been proven to reduce mortality compared with placebo or standard care [5-8].

Effects of probiotics on mortality depend on the kind of probiotics used [26, 27]. Our study was not powered to detect a difference in mortality, and inclusion was prematurely stopped. Therefore, no benefit of SDD versus LAB on mortality could be evaluated. Our data do suggest that not all probiotics administered to critically ill patients result in an increased risk of mortality.

The increased mortality risk in patients with severe pancreatitis and probiotic prophylaxis (16\%) compared with placebo (6\%) [15] could not be confirmed by our trial, which had a similar sample size. There are several differences between our study and the PROPATRIA trial. Firstly, the study populations were different. Secondly, the probiotic L. plantarum $299 / 299$ v differed from the PROPATRIA trial probiotic mixture (six different strains) [15], and the antimicrobial and immunological properties of the different probiotic strains vary greatly [31,32]. Thirdly, patients in the present study received probiotics via nasogastric tubes. In the PROPATRIA trial, nasojejunal tubes were used [15]. Small bowel feeding has been shown to be associated with ischemic bowel disease in patients started on early enteral feeding after an abdominal procedure [33].

One limitation of the present study is the premature ending, which prevented the completion of patient enrolment. Crossover of units was deemed necessary after allocation on a unit level to prevent cross-colonisation $[34,35]$. However, the crossover of units was not completed, resulting in an unequal mix of patients and disease burden, so the adjustments in the analyses, as mentioned above, had to be made. Another limitation could be that the study was not double-blinded, because surveillance cultures reveal on which unit SDD was used and on which unit not. Masking of these cultures would be impossible and unethical since additional antibiotic treatment has to be based on these culture results. Furthermore, one unit was designated the SDD unit and the other the LAB unit to prevent cross-colonisation between SDD and LAB patients. The fact that infections were defined retrospectively may have been a limitation, despite the fact that the examiners were blinded for the preventive treatment assigned to the patients.

A fourth limitation could be that only E. coli and enterococci were isolated from rectal swabs, whereas no oropharyngeal cultures were taken, thereby hampering the classification of infections in endogenous and exogenous. Thus, a concomitant exogenous problem affecting both study groups and causing infections cannot be ruled out.

In conclusion, the 130 critically ill patients receiving probiotics did not show a significantly increased ICU mortality or mortality at day 28 compared with the 124 
patients receiving SDD. On the other hand, there was a tendency towards more infections in patients receiving LAB compared with SDD.

Acknowledgments The authors would like to thank Miranda Hendrikx and Laura Bormans for their excellent assistance as research nurses on this project. They also would like to thank Jerry Townsend for his excellent assistance in data retrieval. We are indebted to all the patients and their relatives for giving informed consent and participating in the trial. The contributions of the involved ICU nurses, ICU staff, and laboratory technicians are very much appreciated. This research was funded by ZonMw (The Netherlands organisation for health research and development), grant no. 6100.0007 .

Open Access This article is distributed under the terms of the Creative Commons Attribution Noncommercial License which permits any noncommercial use, distribution, and reproduction in any medium, provided the original author(s) and source are credited.

\section{References}

1. Inan D, Saba R, Gunseren F, Ongut G, Turhan O, Yalcin AN, Mamikoglu L (2005) Daily antibiotic cost of nosocomial infections in a Turkish university hospital. BMC Infect Dis 5:5

2. Vincent JL (2003) Nosocomial infections in adult intensive-care units. Lancet 361:2068-2077

3. Park DR (2005) The microbiology of ventilator-associated pneumonia. Respir Care 50:742-763 (discussion 763-745)

4. Stoutenbeek CP, van Saene HK, Miranda DR, Zandstra DF (1984) The effect of selective decontamination of the digestive tract on colonisation and infection rate in multiple trauma patients. Intensive Care Med 10:185-192

5. De Jonge E, Schultz MJ, Spanjaard L, Bossuyt PM, Vroom MB, Dankert J, Kesecioglu J (2003) Effects of selective decontamination of digestive tract on mortality and acquisition of resistant bacteria in intensive care: a randomised controlled trial. Lancet 362:1011-1016

6. De La Cal MA, Cerda E, Garcia-Hierro P, van Saene HK, Gomez-Santos D, Negro E, Lorente JA (2005) Survival benefit in critically ill burned patients receiving selective decontamination of the digestive tract: a randomized, placebo-controlled, double-blind trial. Ann Surg 241:424-430

7. De Smet AM, Kluytmans JA, Cooper BS, Mascini EM, Benus RF, van der Werf TS, van der Hoeven JG, Pickkers P, Bogaers-Hofman D, van der Meer NJ, Bernards AT, Kuijper EJ, Joore JC, Leverstein-van Hall MA, Bindels AJ, Jansz AR, Wesselink RM, de Jongh BM, Dennesen PJ, van Asselt GJ, te Velde LF, Frenay IH, Kaasjager K, Bosch FH, van Iterson M, Thijsen SF, Kluge GH, Pauw W, de Vries JW, Kaan JA, Arends JP, Aarts LP, Sturm PD, Harinck HI, Voss A, Uijtendaal EV, Blok HE, Thieme Groen ES, Pouw ME, Kalkman CJ, Bonten MJ (2009)

Decontamination of the digestive tract and oropharynx in ICU patients. N Engl J Med 360:20-31
8. Liberati A, D'Amico R, Pifferi S, Torri V, Brazzi L, Parmelli E (2009) Antibiotic prophylaxis to reduce respiratory tract infections and mortality in adults receiving intensive care. Cochrane Database Syst Rev CD000022

9. Oostdijk EA, de Smet AM, Blok HE, Thieme Groen ES, van Asselt GJ, Benus RF, Bernards SA, Frenay IH, Jansz AR, de Jongh BM, Kaan JA, Leverstein-van Hall MA, Mascini EM, Pauw W, Sturm PD, Thijsen SF, Kluytmans JA, Bonten MJ (2010) Ecological effects of selective decontamination on resistant Gramnegative bacterial colonization. Am $\mathrm{J}$ Respir Crit Care Med 181:452-457

10. Isakow W, Morrow LE, Kollef MH (2007) Probiotics for preventing and treating nosocomial infections: review of current evidence and recommendations. Chest 132:286-294

11. Madsen K (2008) Probiotics in critically ill patients. J Clin Gastroenterol 42(Suppl 3 Pt 1):S116S118

12. Rayes N, Hansen S, Seehofer D, Muller AR, Serke S, Bengmark S, Neuhaus P (2002) Early enteral supply of fiber and lactobacilli versus conventional nutrition: a controlled trial in patients with major abdominal surgery. Nutrition 18:609-615

13. Olah A, Belagyi T, Issekutz A, Gamal ME, Bengmark S (2002) Randomized clinical trial of specific Lactobacillus and fibre supplement to early enteral nutrition in patients with acute pancreatitis. Br J Surg 89:1103-1107

14. Rayes N, Seehofer D, Hansen S, Boucsein K, Muller AR, Serke S, Bengmark S, Neuhaus P (2002) Early enteral supply of Lactobacillus and fiber versus selective bowel decontamination: a controlled trial in liver transplant recipients. Transplantation 74:123-127
15. Besselink MG, van Santvoort HC, Buskens E, Boermeester MA, van Goor $\mathrm{H}$, Timmerman HM, Nieuwenhuijs VB, Bollen TL, van Ramshorst B, Witteman BJ, Rosman C, Ploeg RJ, Brink MA, Schaapherder AF, Dejong $\mathrm{CH}$, Wahab PJ, van Laarhoven CJ, van der Harst E, van Eijck $\mathrm{CH}$, Cuesta MA, Akkermans LM, Gooszen HG (2008) Probiotic prophylaxis in predicted severe acute pancreatitis: a randomised, doubleblind, placebo-controlled trial. Lancet 371:651-659

16. Garner JS, Jarvis WR, Emori TG, Horan TC, Hughes JM (1988) CDC definitions for nosocomial infections. Am J Infect Control 16:128-140

17. Linssen CF, Jacobs JA, Schouten JS, van Mook WN, Ramsay G, Drent M (2008) Influence of antibiotic therapy on the cytological diagnosis of ventilator-associated pneumonia. Intensive Care Med 34:865-872

18. Clinical Laboratory Standards Institute (2006) Methods for dilution antimicrobial susceptibility tests for bacteria that grow aerobically-seventh edition: approved standard M7-A7. CLSI, Wayne, PA

19. WHO Collaborating Centre for Drug Statistics Methodology (2006) Anatomical therapeutic chemical (ATC) classification index with defined daily doses (DDDs). WHO Collaborating Centre, Oslo, Norway

20. Filius PM, Liem TB, van der Linden PD, Janknegt R, Natsch S, Vulto AG, Verbrugh HA (2005) An additional measure for quantifying antibiotic use in hospitals. J Antimicrob Chemother 55:805-808

21. Bonten MJ, Kullberg BJ, van Dalen R, Girbes AR, Hoepelman IM, Hustinx W, van der Meer JW, Speelman P, Stobberingh EE, Verbrugh HA, Verhoef $\mathrm{J}$, Zwaveling JH, Consultants of the Dutch Working Group on Antibiotic Policy (2000) Selective digestive decontamination in patients in intensive care. J Antimicrob Chemother 46:351-362 
22. Puffer S, Torgerson D, Watson J (2003) Evidence for risk of bias in cluster randomised trials: review of recent trials published in three general medical journals. BMJ 327:785-789

23. Campbell MK, Elbourne DR, Altman DG (2004) CONSORT statement: extension to cluster randomised trials. BMJ 328:702-708

24. Knaus WA, Draper EA, Wagner DP, Zimmerman JE (1985) APACHE II: a severity of disease classification system. Crit Care Med 13:818-829

25. Garrouste-Orgeas M, Troche G, Azoulay E, Caubel A, de Lassence A, Cheval C, Montesino L, Thuong M, Vincent F, Cohen Y, Timsit JF (2004) Body mass index. An additional prognostic factor in ICU patients. Intensive Care Med 30:437-443

26. Jain PK, McNaught CE, Anderson AD, MacFie J, Mitchell CJ (2004) Influence of synbiotic containing Lactobacillus acidophilus La5, Bifidobacterium lactis Bb 12, Streptococcus thermophilus, Lactobacillus bulgaricus and oligofructose on gut barrier function and sepsis in critically ill patients: a randomised controlled trial. Clin Nutr 23:467-475
27. Kotzampassi K, Giamarellos-

Bourboulis EJ, Voudouris A, Kazamias P, Eleftheriadis E (2006) Benefits of a synbiotic formula (Synbiotic 2000Forte) in critically ill trauma patients: early results of a randomized controlled trial. World J Surg 30:1848-1855

28. Krueger WA, Lenhart FP, Neeser G, Ruckdeschel G, Schreckhase H, Eissner HJ, Forst H, Eckart J, Peter K, Unertl KE (2002) Influence of combined intravenous and topical antibiotic prophylaxis on the incidence of infections, organ dysfunctions, and mortality in critically ill surgical patients: a prospective, stratified, randomized, double-blind, placebocontrolled clinical trial. Am J Respir Crit Care Med 166:1029-1037

29. Heininger A, Meyer E, Schwab F, Marschal M, Unertl K, Krueger WA (2006) Effects of long-term routine use of selective digestive decontamination on antimicrobial resistance. Intensive Care Med 32:1569-1576

30. SWAB (2009) NethMap 2009consumption of antimicrobial agents and antimicrobial resistance among medically important bacteria in The Netherlands. http://www.swab.nl/ swab/cms3.nsf/viewdoc/2E7389A339 73953BC12575D1002A01C3. Accessed 03 March 2010
31. Timmerman HM, Niers LE, Ridwan BU, Koning CJ, Mulder L, Akkermans LM, Rombouts FM, Rijkers GT (2007) Design of a multispecies probiotic mixture to prevent infectious complications in critically ill patients. Clin Nutr 26:450-459

32. Bengmark S (2004) Synbiotics to strengthen gut barrier function and reduce morbidity in critically ill patients. Clin Nutr 23:441-445

33. Melis M, Fichera A, Ferguson MK (2006) Bowel necrosis associated with early jejunal tube feeding: a complication of postoperative enteral nutrition. Arch Surg 141:701-704

34. Bonten MJ, Kluytmans J, De Smet AM, Bootsma M, Hoes A (2003) Selective decontamination of digestive tract in intensive care. Lancet 362:2118-2119 (author reply 2119-2120)

35. Verbrugh HA (2003) Selective decontamination of digestive tract in intensive care. Lancet 362:2117-2118 